\title{
The relationship between important reproductive health indices and human development index in Iran
}

\author{
Hamideh Sabet Rohani*1, Alireza Ahmadvand ${ }^{2}$, Gholamreza Garmaroudi ${ }^{3}$ \\ Received: 15 Jan 2018 \\ Published: 30 June 2018
}

\begin{abstract}
Background: Reviewing the reproductive health indicators (RHIs) provides the possibility of periodic health system performance evaluation to achieve balanced development. This study aimed to determine the trend of ten reproductive health indicators changes during 2002-2011, and examining their relationship with the Human Development Index (HDI).

Methods: In this ecological study the trend of ten reproductive health indicators from five selected provinces of Iran were mapped. Then the relationship of these ten indicators with HDI was investigated using non parametric Spearman's rank correlation coefficient in SPSS v. 20.

Results: There was a statistically significant direct and strong correlation between the percentage of childbirth by a trained person and HDI $(\mathrm{r}=0.9, \mathrm{p}=0.037)$
\end{abstract}

Conclusion: In our study, it can be expected that the provinces with similar reproductive health indicators, likely have similar HDI.

Keywords: Reproductive health indices, Human development index, Ecological study

Copyright $₫$ Iran University of Medical Sciences

Cite this article as: Sabet Rohani $\mathrm{H}$, Ahmadvand A, Garmaroudi Gh. The relationship between the important reproductive health indices and human development index in Iran. Med J Islam Repub Iran. 2018 (30 June);32:54. https://doi.org/10.14196/mjiri.32.54

\section{Introduction}

Evaluating the trend of reproductive health indicators (RHIs) such as infant mortality rate (IMR) or maternal mortality rate (MMR) and their communication and interaction with indicators of development allows health policy makers at regular intervals, be able to obtain correct analysis of health system performance and provide better programs for the management of risk factors (1). Despite the favourable trends in the field of reproductive health indicators in the country, disparities in this area, is still seen in the provinces (2).

Therefore, the possible association of human development with RHIs is of such issues that require further examination. This study aimed to determine the trend of the RHIs in five selected provinces of the country has been done during 2002-2011. In addition, the relationships between each of these indicators with human development

Corresponding author: Hamideh Sabet Rohani, hamidehsabetrohani@gmail.com

1. Department of Community Medicine, School of Medicine, Iran University of Medical Sciences, Tehran, Iran.

2. Global Health Clinical Research Training Fellow, Imperial College London, London, UK, \& Non-Communicable Diseases Research Center, Tehran University of Medical Sciences, Tehran, Iran.

3. Department of Health Education and Promotion, School of Public Health, Tehran University of Medical Sciences, Tehran, Iran. index (HDI) were examined.

\section{Methods}

Present research is an ecological study that has been designed based on secondary data and available statistics on official sources and using expert's opinion. Five provinces, including Bushehr, Tehran, Sistan-Baluchestan, Kurdestan and Golestan were selected for data collection that consisted of different levels of human development. Information for both RHIs and HDI were gathered from these provinces and used for final analysis.

Age, sex and years of education in the population of selected provinces were considered as demographic variables, along with. The ten main indicator of reproductive health, including population growth, family size, mean marriage age for men and women, total fertility rate

$\uparrow$ What is "already known" in this topic:

Most of health indicators have been improved in Iran in recent decades. The HDI as a composite indicator reflects the most basic human abilities, namely long life, awareness and enjoyment of a good and quality of life.

$\rightarrow$ What this article adds:

We showed that health indicators in Iran are consistent with the human development index, although this development is not balanced in all provinces. However, it seems that the provinces with similar RHIs have similar HDI, and thereby, similar development. 
(TFR), crude birth rate (CBR), infant mortality rate (IMR), maternal mortality rate (MMR), the percentage of safe and healthy place of childbirth and the percentage of childbirth by a trained person, were analysed as independent variables and finally, HDI analysed as the dependent variable.

Secondary data used were obtained from four main sources of: official census results from Iran's National Bureau of Statistics, official reports from National Organization for Civil Registration (NOCR) and the Ministry of Health and Medical Education and scientific researches. All data analysis determined by expert were included in this study.

For demographic variables, age distribution was set on 7 categories and education on 8 categories and then Compound Annual Growth Rate (CAGR) was calculated for both. Finally, to determine the relationship between RHIs and HDI, we used "Harmonic Mean" for adjusting the speed of different growth of indicators in the mentioned years. Then the trends of these variables, during the period of ten years were determined by province separation.

In analysis section, the relationship between RHIs with HDI was measured by non-parametric Spearman correlation coefficient statistical method in software SPSS (SPSS Inc., USA) version 20 (At the level of significance, $\mathrm{p}<0.05) 16$.

\section{Results}

The results of this study was based on the data associated with point estimate of 199 province-year from 10 independent variables (RHIs) and one independent variable (HDI) 11 independent and dependent variables during the period of 10 years.

The population growth rate in our study showed the various trend in five provinces. At the end of the study period, this rate in Kurdistan was the lowest $(0.73 \%)$ whereas in Bushehr was the highest (3.11\%).

The family size indices showed a downward trend in each of the five provinces with the lowest average family size reported from Tehran (3.7) and the highest was reported from Sistan-Baluchestan (5).

The trend of the mean marriage age in five provinces for women and men has increased during the study so that during one decade of our study, the average of marriage age in women increased from 20.6 to 23.1 and in men increased from 24.4 to 26.2 .

The trend of TFR in four provinces except SistanBaluchestan had similar slope and slowly declined. At the end of the study period, five provinces in terms of TFR showed more convergence. At this time, TFR was reported in Sistan- Baluchestan 3 and in Tehran 1.8.

The trend of the crude birth in both Kurdestan and Tehran was decreased while in other increased. At the end of the study period, this index in Tehran was the lowest (14.9) and in Sistan-Baluchestan was the highest (31.7).

The IMR trend in each of five provinces showed a rapid decline. During the study, the average reduction in IMR of five provinces, has reported to less than half so, the average annual index of 5 provinces decreased from 44.78 to 12.36 .
The trends of MMR in five provinces have a sinusoidal pattern, with consecutive increases and decreases. During the study, the highest provincial average of this indicator was reported from Sistan-Baluchistan (51.2) and the lowest average from Tehran (14.9).

The trend of two indicators including: the percentage of safe and healthy place of childbirth and the percentage of childbirth by a trained person generally in provinces increased. However, the percentage of these indicators in Sistan-Baluchestan was 1.4 times lower than the average of other provinces. During the study, the lowest provincial average of last indicator was reported from SistanBaluchistan $(65.3 \%)$ and the highest provincial average from Bushehr (97.7\%).

Finally, in our study, in the five selected provinces, the trend of the human development index increased uniformly over a decade. In the last year of our study, Tehran (0.839), Bushehr (0.781), Golestan (0.739), Kurdistan (0.695) but Sistan-Baluchistan (0.646), had the range of the highest to lowest HDIs.

Based on the statistical analysis, totally six independent variables IMR, MMR, crude birth, TFR, family size and population growth had inverse correlation with the HDI but other independent variables had direct correlation with the HDI.

The percentage of childbirth by a trained person was the only independent variable that had direct and strong correlation with HDI, and hence statistically significant $(\mathrm{r}=0.9, \mathrm{p}=0.037)$.

\section{Discussion}

Based on our study, the trend of HDI had balanced and gradual increased in provinces. The report of UNDP (3) represents the increasing growth in indicators of development in Iran. Because of joined collection of countries existed with high human development index (HHDI). According to data from the WHO, which is mentioned in Movahedi et al (4) study: the annual decline rate of U5MR in Iran from 1990 until 2005 was 2.5 which are much greater than the corresponding number in countries with MHDI. On the other hand annually, TFR dropped $0.20 \%$ while even in HHDI this figure was $0.15 \%$. In fact, the improvement of this indicator was much steeper in Iran than other countries in EMR. In the study of Boutayeb \& Sergini (5) on health indicators and human development in the Arab region showed that high-income countries in this region had similar HIDs. Nonetheless, they had high life expectancy, low levels of: lost healthy years, maternal mortality, infant mortality and underweight children. Populations of these countries had good access to education and health. The results of Koohi et al (6), Abolhallaje M (7), Jafari et al (8) and Kiadaliri et al (9) have reported similar results with our study on the trend of the HDI.

In our study, there was a statistically significant relationship between HDI and the percentage of childbirth by a trained person $(\mathrm{p}=0.037)$. Arshad Malik and Kayani (10) by comparing the fifth ideal of MDG from 2000 to 2010 reported that the percentage of childbirth by a trained person in Iran was $97 \%$. However, according to Soori et al (11), the percentage of childbirth by a trained person be- 
tween 2006 until 2013 in the world was 73\%, in the EMRO region $58 \%$, and in Iran 99\%. Olyaee Manesh et al (12) in 2009 have reported that the strongest correlation found between the year and the percentage of childbirth by an untrained person. Lankarani et al (13) in 2007 showed a significant difference in inequality indices of safe childbirth, with socioeconomic factors.

In our study MMR trends from five provinces were sinusoidal. Olyaee Manesh et al (12) has showed that MMR is reflecting the socio-economic conditions of each community. Similar to our study, Mohammad Nabi et al (14) and Lankarani et al (13) referred to the presence of inequality of this indicator in various provinces. According to Soori et al (11), the MMR in Iran has dropped from 83 to 23 per 100,000 live births in 23 years (1993-2016).

In this study, IMR showed a rapid decline associated with convergence. The report of world population data (15) in 2014 referred to the decline of mentioned index in Iran from 139 to 16 per thousand. A similar decline has been reported by Soori et al (11). Rezaei et al (16) demonstrated a significant relationship between annual income and IMR ( $p=0.005)$. However, in our study, there was no significant relationship between HDI and IMR $(p=0.104)$.

The trend of TFR during the study period was declining in five provinces. According to Movahedi et al (4) study in 2005 the estimated TFR in Iran was very close to TFR in HHDI countries (1.95\%). Also Olyaee Manesh et al (12) findings was similar to this study showed that the crude birth rate almost remained constant and this trend is likely to continue in the coming years.

A study conducted by Tode Falah and Kazemipour (17), Jafari et al (8), Gotabi and Ghafari (18) showed the growing trend of delay in marriage age for women. Gotabi and Ghafari (18) also quoted by Colwell noted that marriage patterns in any society, reflecting the cultural context and socio-economic changes in the community.

Similar to our study, results of Lutz (19)and Central Bank of the Islamic Republic of Iran (20) reported that the family size in provinces has relatively reduced (5).

\section{Limitations}

The researchers were faced with restrictions such as multiple data sources, point estimates report rather than confidence intervals, reporter resource constraints of reproductive health indicators by province separation (11). These limitations were minimized by using scientific methods and electronic resources through search in reliable sources of information. Moreover for the prevention of ecological fallacy, researchers have refused from generalization of the results at the individual level (4).

\section{Conclusion}

In our study, HDI and RHIs showed variations in the different regions and provinces of the country. One would expect the provinces with similar RHIs; have similar HDI, and thereby similar development. It is necessary that the subsequent studies be done in all provinces.

\section{Acknowledgment}

This article is adapted from the first author's thesis in MPH modular courses on reproductive health.

Conflict of Interests

The authors declare that they have no competing interests.

\section{References}

1. Khosravi A, Rahbar MR. Health profile indicators in the Islamic Republic of IRAN, Ministry of health \& medical education deputy for health, 2009.

2. Salazar Ch. Indicators of children's health is unequal in different provinces of IRAN. Fars news agency: Tehran. 2007. Available from:(http://www.farsnews.com/newstext.php?nn=8611020577)

3. United Nations Development Programme, Human Development Report, 1 UN Plaza, New York, NY 10017, USA: New York. 2013:165-181.

4. Movahedi M, Haghdoost AA, Pournik O, Hajarizadeh B, Fallah MS. Temporal variations of health indicators in Iran comparing with other Eastern Mediterranean Region countries in the last two decades. J Public Health- Uk. 2008; 30(4):499-504.

5. Boutayeb A, Serghini M. Social inequalities, regional disparities and health inequity in North African countries. Int J Equity Health. 2011; $10: 23$

6. Koohi F, Nedjat S, Yaseri M, Cheraghi Z. Quality of Life among General Populations of Different Countries in the Past 10 Years, with a Focus on Human Development Index: A Systematic Review and Meta-analysis. Iran J Public Health. 2017 Jan; 46(1):12-22.

7. Abolhallaje M, Mousavi SM, Anjomshoa M, Beigi Nasiri A, Seyedin $\mathrm{H}$, Sadeghifar J, et al. Assessing Health Inequalities in Iran: A Focus on the Distribution of Health Care Facilities. Glob J Health Sci. 2014 Jul;6(4):285-291

8. Jafari F, Eftekhar H, Pourreza A, Mosavi J. Socio- economic and medical determinants of low birth weight in Iran: 20years after establishment of a primary healthcare network. Public Health. 2010 Mar; 124(3):153-158.

9. Ahmad Kiadaliri A, Najafi B, Haghparast-Bidgoli H. Geographic distribution of need and access to health care in rural population: an ecological study in Iran. Int J Equity Health. 2011; 10:39.

10. Arshad Malik MF, Kayani MA. Issues of maternal health in Pakistan: trends towards millennium development goal 5. J Pak Med Assoc . 2014. 64(6): 691-693.

11. Soori H, Hasani J, Entezami N, Hooseini SM, Rafiei M. Assessment of Millennium Development Goals Indicators (MDGs) in Iran, Eastern Mediterranean Region and the World: A Study Emerging from The MDGs Report 2014. Iranian J Epidemiol. 2017;13(1):41-51.

12. Olyaee Manesh A, Haghdoost AA, Beheshtian M, Tehrani Banihashemi A , Motlagh M. Progress towards Health Equity in I.R. of Iran through Last Three Decades. Iran J Public Health. 2009;38(1):130-135.

13. Lankarani KB, Alavian SM, Peymani P. Health in the Islamic Republic of Iran, challenges and progresses. Med J Islam Repub Iran. 2013 Feb;27(1):42-49.

14. Mohammad Naby S. Improving Mortality of Mothers in Iran and its Comparison with Arabic Countries. Iran and Arab Friendship Association, UPR-Iran February 2010.

15. World Population Data Sheet, Population Reference Bureau: Washington, DC. 2014.

16. Rezaei f, Noori A, Haghdoost AA, Shokoohi M. Ecological Study of the relationship between rural area income in the country and health indicies. Payesh Journal. 2011;1:5-11.

17. Toode Falah M, Kazemipour Sh. Effect of modernization on marriage age in the country \& seven selected province With an emphasis on demographic characteristics. Social Res Quart. 2010;8: 106-128.

18. Habibpoor Gotabi K, Ghafari Gh. The causes of the increase in age of marriage for girls. Women Develop Politic. 2011;9(1):7-34.

19. Lutz W, Cuaresma JC, Abbasi-shavazi MJ. Demography, Education, and Democracy: Global Trends and the case of Iran. Popul Dev Rev. First published: 16 June 2010.

20. Economic Statistics Department. Survey according to the results of the household budget in urban areas of Iran 2009-2010. Central Bank 
Reproductive health indices and HDI in Iran

of the Islamic Republic of Iran: Tehran. 2011. 